\title{
Duas novas espécies de Simpulopsis (Gastropoda, Bulimulidae) para o Rio Grande do Sul, Brasil ${ }^{1}$
}

\author{
Letícia F. da Silva ${ }^{1} \&$ José W. Thomé ${ }^{2}$
} 1. Parte da Dissertação de Mestrado da autora sênior, Programa de Pós-graduação em Zoologia, Pontifícia Universidade Católica do
Rio Grande do Sul (PUCRS).
2. Laboratório de Malacologia, Faculdade de Biociências, Pontifícia Universidade Católica do Rio Grande do Sul (PUCRS), Av.
Ipiranga, 6681, prédio 12-D, sala 340, 90619-900 Porto Alegre, RS, Brasil. (lfs_malaco@ hotmail.com)

\begin{abstract}
Two new species of Simpulopsis (Gastropoda, Bulimulidae) from Rio Grande do Sul, Brasil. Simpulopsis promatensis and S. gomesae, two new species from São Francisco de Paula, Rio Grande do Sul state, Brazil are described. Conchology, conchiliometry and soft-part morphology, including jaw, radula, reproductive and pallial systems are provided.
\end{abstract}

KEYWORDS. Simpulopsis, new species, anatomy, morphology, conchiliometry.

RESUMO. Simpulopsis promatensis e S. gomesae, duas novas espécies para São Francisco de Paula, Rio Grande do Sul, Brasil, são descritas. São apresentadas a conquiliologia, conquiliometria e morfologia das partes moles, incluindo mandíbula, rádula, sistemas reprodutor e palial.

PALAVRAS-CHAVE. Simpulopsis, novas espécies, anatomia, morfologia, conquiliometria.

O gênero Simpulopsis Beck, 1837 distribui-se na América do Sul e Central (Breure, 1979). Subdivide-se em dois subgêneros, sendo um nominal e o outro denominado Eudioptus Albers, 1860 [=Bulimulopsis Pilsbry, 1899; =Bulimolopsis Parodíz, 1944 (grafia errada de Bulimulopsis Pilsbry, 1899)]; Pseudoglandina Weyrauch, 1967 [espécie-tipo (por monotipia): Pseudoglandina agitata Weyrauch]; Paracochlea Hylton-Scott, 1967 [espécie-tipo (por monotipia): Bulimulus (Paracochlea) willineri Hylton-Scott] (Breure, 1979; Thiele, 1963). Salgado \& Coelho (2003) elevaram Eudioptus a gênero sem fornecer justificativa. O subgênero nominal caracteriza-se por sua concha arredondada, extremamente delgada, amarelo-esverdeada a olivácea, com 3-41/2 voltas, geralmente um pouco enrugada; altura de 9 a 25 mm (THIELE, 1963; ZILCH, 1960; BREURE, 1979).

Conhecem-se 11 espécies de Simpulopsis s. str. para a América do Sul. Breure (1979) mencionou 13 espécies para essa mesma região, no entanto, não considerou duas sinonimizações anteriores. PILSBRy (1899) indicou $S$. membranacea (Villa, 1841) como sinônimo de $S$. sulculosa (Férussac, 1821); SмIтн (1896) sinonimizou S. corrugata Guppy, 1866 a S. rufovirens (Moricand, 1846). Têm-se informações sobre a rádula, o sistema reprodutor e a cavidade palial em apenas cinco espécies: $S$. miersi (Pfeiffer, 1853) [localidade-tipo: Espírito Santo], S. ovata (Sowerby, 1822) [Petrópolis, Rezende, Itatiaia, Sumaré, RJ; São Francisco de Paula, RS], S. pseudosulculosa Breure, 1975 [localidade-tipo: Nova Teutônia, SC], S. sulculosa (Férussac, 1821) [Nova Teutônia, SC], $S$. wiebesi Breure, 1975 [localidade-tipo: Nova Teutônia, SC] (ARAúJo, 1975; AraúJo \& BREuRE, 1977; Gomes et al., 2004; Breure, 1975; Breure \& Ploeger, 1977). A maioria das espécies deste gênero possui descrições sucintas, embasadas na descrição conquiliológica de um único espécime (Pilsbry, 1899; Pfeiffer, 1848, 1853, 1856a, 1856b, 1856c, 1858, 1859, 1861a, b, 1868, 1876; MoRICAND, 1836, 1846; REEVE, 1849, 1862).

Este trabalho visa enriquecer o conhecimento sobre os gastrópodes pulmonados encontrados no CPCN/ PRÓMATA, apresentando duas novas espécies de Simpulopsis.

\section{MATERIAL E MÉTODOS}

Os exemplares foram coletados sobre as folhas de arbustos e arvoretas em áreas de floresta mista e ombrófila densa do CPCN/PRÓ-MATA, entre 1997 e 2003. O Centro de Pesquisas e Conservação da Natureza PRÓ-MATA (CPCN-PM) (29²8’ S; 50¹0’ W) compreende cerca de 4.500 ha e está situado a aproximadamente $900 \mathrm{~m}$ de altitude, na borda leste da região geomorfológica do Planalto das Araucárias (São Francisco de Paula, Rio Grande do Sul), onde ocorre o encontro de três regiões fitoecológicas: Floresta Ombrófila Mista, Floresta Ombrófila Densa (Mata Atlântica) e Savana. O clima nesta região é classificado como superúmido, com índices pluviométricos variando entre 1.750 a $2.500 \mathrm{~mm}$ anuais (BERTOLETTI \& TeIXEIRA, 1995). Coletaram-se 77 exemplares de Simpulopsis; os espécimes vivos foram distendidos em água destilada e conservados em álcool $70^{\circ} \mathrm{GL}$. Os lotes foram incorporados ao Museu de Ciências e Tecnologia (MCP), Museu de Ciências Naturais da Fundação Zoobotânica do Rio Grande do Sul (MCN-FZB), alguns foram doados ao British Museum of Natural History, Londres, Inglaterra (BMNH) e ao Swedish Museum of Natural History, Estocolmo, Suécia (SMNH). Abreviatura utilizada: J. Thomé/ELMP (José Willibaldo Thomé/Equipe do Laboratório de 


\section{Malacologia da PUCRS).}

Para a caracterização anatômica, cinco espécimes com mais de três voltas, de cada espécie, foram dissecados sob estereomicroscópio com câmara lúcida acoplada, possibilitando a descrição e o desenho do sistema reprodutor e da cavidade palial.

O estudo conquiliomorfométrico foi realizado com 62 espécimes de Simpulopsis. Estudaram-se 12 variáveis (Fig. 1) a partir de três marcos anatômicos (a: ápice, b: junção entre a margem interna e a externa, e c: junção entre a margem parietal e a columelar), denominadas como: distância entre o ápice e a margem parietal superior (Dap),

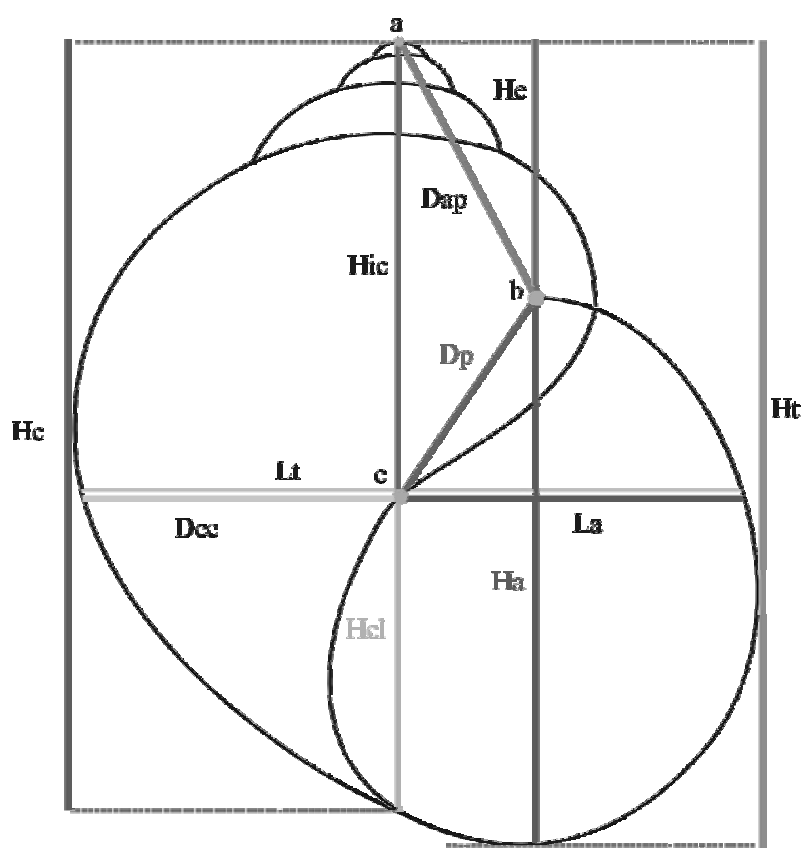

Fig. 1. Desenho esquemático da concha de Simpulopsis (a, ápice; b, junção entre o lábio externo e o interno; c, junção entre o lábio parietal e o columelar; Dap, distância entre o ápice e a junção da margem parietal superior; Dce, distância entre c e a extremidade; Dp, distância entre a junção da margem parietal superior e a inferior; Ha, altura da abertura; Hc, altura central; Hcl, altura da columela livre; He, altura da espira; Hic, altura interna da columela; Ht, altura total; La, largura da abertura; Lt, largura total). distância entre c e a extremidade (Dce), distância entre a margem parietal superior e inferior (Dp), altura da abertura $(\mathrm{Ha})$, altura central $(\mathrm{Hc})$, altura da columela livre $(\mathrm{Hcl})$, altura da espira (He), altura interna da columela (Hic), altura total (Ht), largura da abertura (La), largura total (Lt) e o número de voltas $\left(\mathrm{N}^{\circ} \mathrm{vol}\right)$ que foi transformado em frações decimais para fins estatísticos (Fig. 2). A análise estatística restringiu-se ao cálculo das médias e dos desvios padrões para cada variável.

A mandíbula e a rádula de cinco espécimes de cada espécie foram extraídas do bulbo bucal sob estereomicroscópio e limpas com hipoclorito de sódio diluído em água destilada, desidratadas em uma série crescente de álcool $\left(70^{\circ}, 80^{\circ}\right.$ e $\left.96^{\circ} \mathrm{GL}\right)$ e acondicionadas sobre stubs com fita dupla face de carbono, conforme PloEger \& BREURe (1977). A fórmula-fileira da rádula foi expressa a partir de uma adaptação de Breure (1979). Para o estudo da superfície da concha, foram utilizados cinco exemplares de cada espécie. Realizou-se a incisão total do músculo columelar e assim, o corpo pôde ser inteiramente removido da concha sem danificá-la. As conchas foram limpas com água destilada, álcool $70^{\circ} \mathrm{GL}$ e nitrogênio gasoso; quando secas, fixadas em stubs sobre fita dupla face de carbono e cola prata. A partir das fotomicrografias obtidas sob o microscópio eletrônico de varredura (MEV) do Centro de Microscopia e Microanálise da PUCRS, descrevem-se a mandíbula, a rádula e a superfície da concha.

\section{Bulimulidae Tryon, 1896}

\section{Simpulopsis Beck, 1837:100}

Espécie-tipo: Helix sulculosa Férussac, 1821 [estampa: $11^{\mathrm{A}}$, fig. 6 = Vitrina sulculosa Férussac \& Deshayes, 1851 vol.2, pág.96 ] [designação subseqüente por Gray, 1847:171 como Simulopsis (grafia errônea) e emenda por Albers in Martens, 1860: 309].

\section{Simpulopsis promatensis sp. nov. (Figs. 3-18)}

Etimologia. O nome refere-se ao local onde esta espécie foi primeiramente registrada, o Centro de
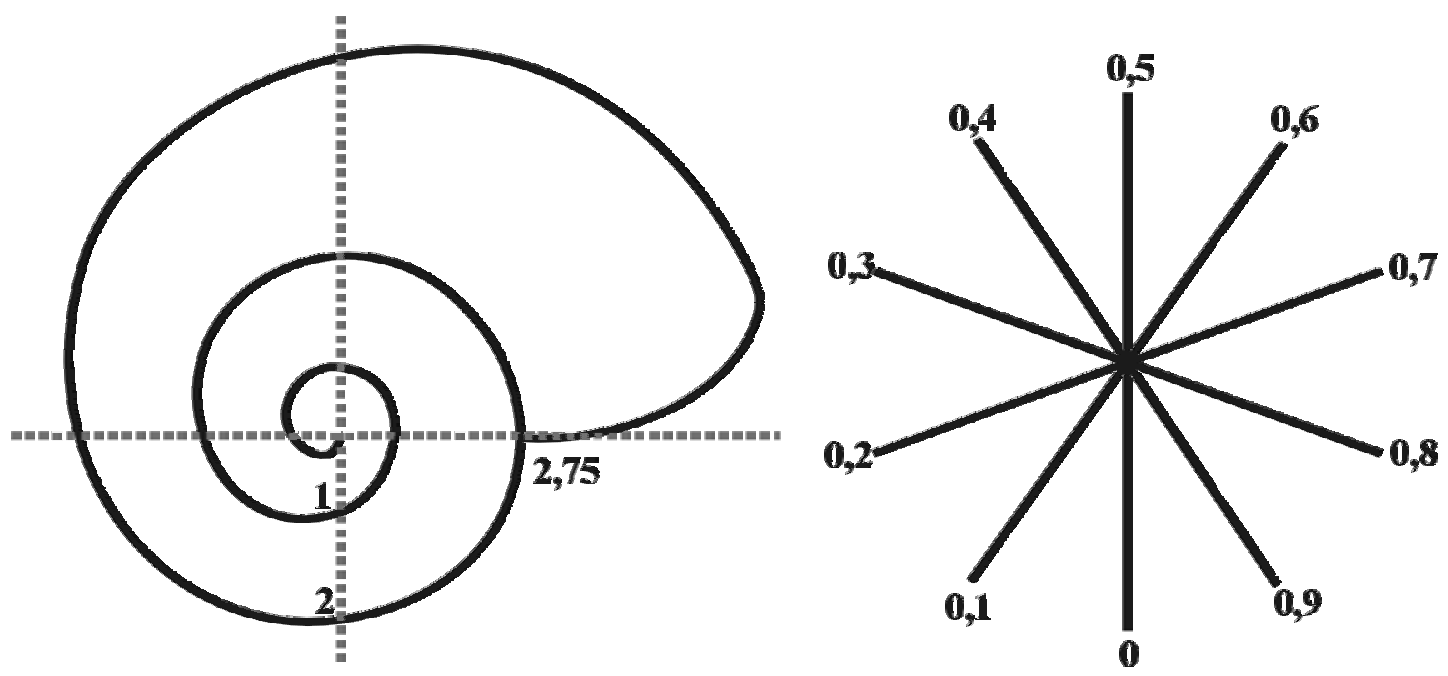

Fig. 2. Método de contagem das voltas e de obtenção das frações decimais. 
Pesquisas e Conservação da Natureza PRÓ-MATA (São Francisco de Paula, RS, Brasil).

Diagnose. Concha marrom, levemente espessa e com calo columelar. Protoconcha com estrias espirais regularmente distribuídas e cruzadas por estrias axiais. Teleoconcha com estrias espirais interrompidas e irregularmente distribuídas, rugosidade axial retilínea, acentua-se gradativamente a cada volta. Corpo marrom, mais escurecido na região nucal, omatóforos negros. $\mathrm{Na}$ região central da rádula, fileiras transversais dos dentes centrais (DC) e laterais (DL) dispõem-se levemente em forma de "V"; dentes marginais (DM) dispostos linearmente. Laterais e marginais têm tamanhos semelhantes, centrais são menores. Centrais e marginais tricúspides; laterais bicúspides. Vesícula seminal cuja largura corresponde a cerca do triplo do ovulispermioducto, ducto da glândula gametolítica com região mediana tendo o dobro da largura inicial e forma ovalada; glândula gametolítica com cerca de um terço do comprimento de seu ducto e ovalada; evertofalo dilatado e com cerca da metade do comprimento do epifalo espiralado; a vagina, na mesma altura, recebe o falo e emite o ducto da glândula gametolítica.
Material-tipo. BRASIL, Rio Grande do Sul: São Francisco de Paula, J. Thomé/ELMP col.: Holótipo. 07.IX.2003 (MCP 8674). Parátipos. 1 ex., 21.II.1997 (MCP 7515); 3 exs., 21.XI.1998 (MCP 7778); 5 exs., 07.IV.2001 (MCP 7929); 1 ex., 07.IV.2001 (SMNH 6078 ex MCP 7929); 1 ex., 07.IV.2001 (MCP 8675); 1 ex., 30.VI.2001 (MCP 8684); 1 ex., 01.VII.2001 (MCP 8678); 3 exs., 01.VII.2001 (MCP 8685); 1 ex., 29.VIII.2001 (MCP 7943); 1 ex., 29.VIII.2001 (MCN-FZB 35547); 10 exs., 12.X.2001 (MCP 8677); 1 ex., 12.X.2001 (MCP 8686); 1 ex., 12.X.2001 (MCP 8730); 2 exs., 13.X.2001 (MCP 8681); 1 ex., 14.X.2001 (MCP 8682); 5 exs., 04.VIII.2002 (MCP 8680); 1 ex., 08.IX.2002 (MCP 8687); 6 exs., 13.X.2002 (MCP 8679); 1 ex., 12.IV.2003 (MCP 8683); 5 exs., 27.IX.2003 (MCP 8676); 6 exs., 28.IX.2003 (MCP 8673).

Localidade-tipo. Centro de Pesquisas e Conservação da Natureza PRÓ-MATA, São Francisco de Paula, RS, Brasil.

Descrição. Corpo marrom, mais escurecido na região nucal, omatóforos negros (Fig. 3). Concha cônica globosa $(\mathrm{Ht} / \mathrm{Lt}=1,15)$, volta corporal ampla; espira com cerca de um terço da altura total $(\mathrm{He} / \mathrm{Ht}=0,30)$; columela oblíqua, imperfurada; abertura ovalada $(\mathrm{Ha} / \mathrm{La}=1,37 ; \mathrm{Ha} /$ $\mathrm{Lt}=0,80 ; \mathrm{La} / \mathrm{Lt}=0,58$ ) (Tab. I), lábio externo cortante; concha marrom, suavemente espessa, translúcida, calo columelar presente (Figs. 4, 5). Protoconcha com 1,75 a 2

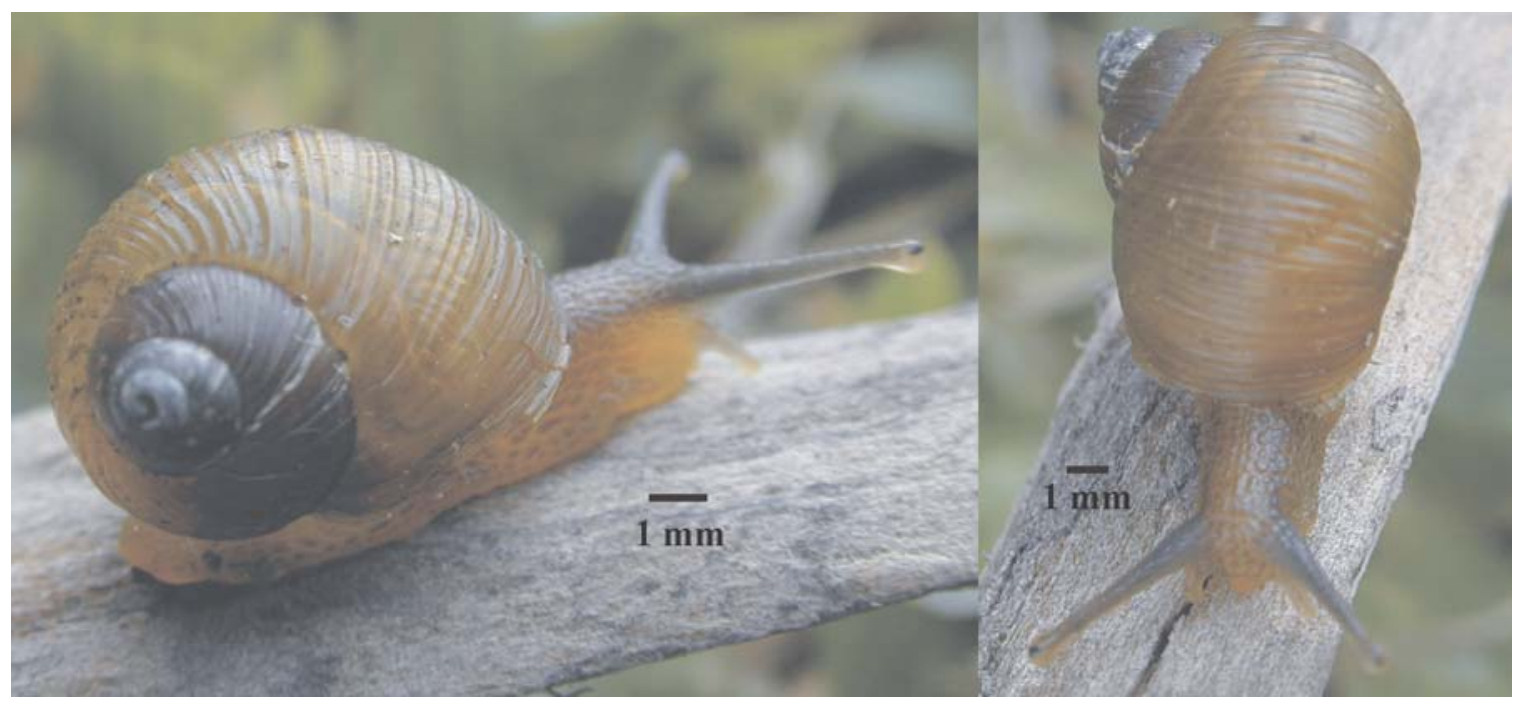

Fig. 3. Espécimes vivos de Simpulopsis promatensis sp. nov.

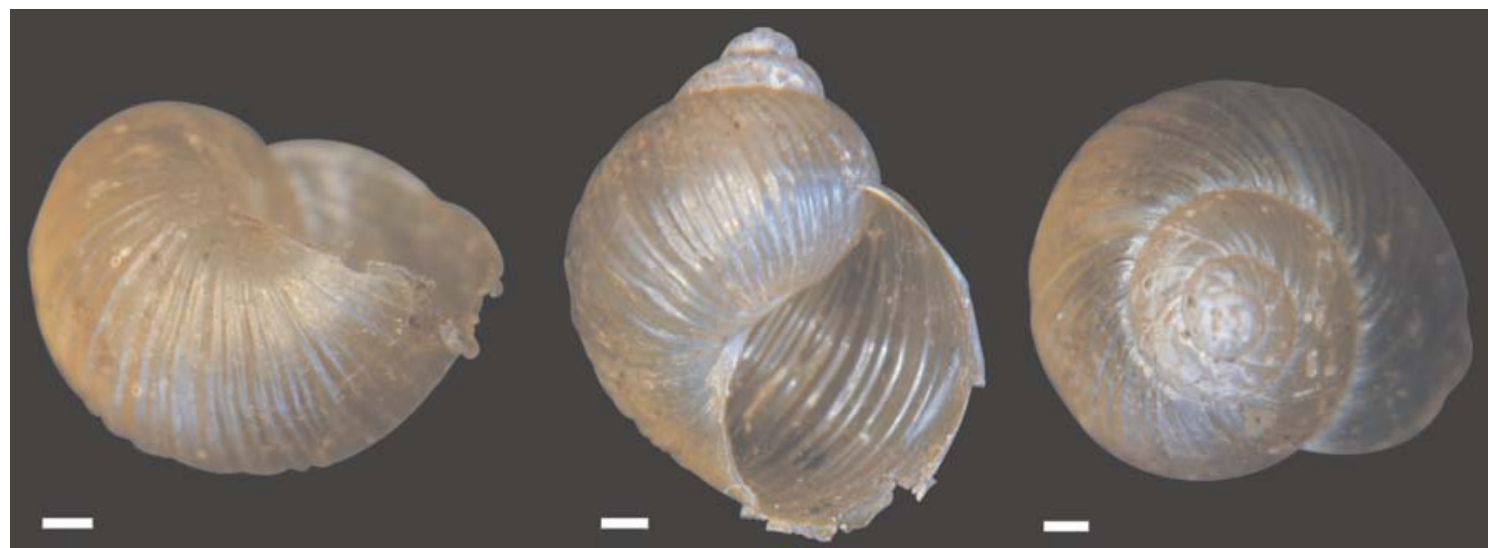

Fig. 4. Holótipo de Simpulopsis promatensis sp. nov. nas posições, da esquerda para a direita: inferior, frontal e apical. Escalas $1 \mathrm{~mm}$. 
voltas, esculturada por delgadas estrias espirais retilíneas regularmente distribuídas e cruzadas por estrias axiais (Figs. 6, 7). Teleoconcha com estrias espirais interrompidas e irregularmente distribuídas (Figs. 8-10); rugosidade axial retilínea, acentuando-se gradativamente a cada volta.

Mandíbula. Arqueada; 26 a 27 ripas retangulares. Região central com ripas idênticas entre si, distinguindose das demais, cuja largura e altura são maiores (Fig. 11).

Rádula. Na região central da rádula, as fileiras transversais dos dentes centrais e laterais dispõem-se levemente em forma de "V"; dentes marginais dispostos linearmente (Fig. 12). Dentes laterais e marginais com tamanhos semelhantes, os centrais são menores. Dentes centrais tricúspides, tendo mesocono lanceolado, ectoconos idênticos, levemente menores do que o mesocono; apresentam duas projeções laterais na placa basal (Fig. 13). Dentes laterais bicúspides, mesocono alongado com extremidade arredondada que pode ser irregularmente recortada; ectocono triangular, com aproximadamente a metade do comprimento do mesocono; placa basal com projeção abaixo do ectocono (Fig. 14). Gradativa diferenciação dos dentes laterais aos marginais, caracterizando uma série de transição (Fig. 15). Dentes marginais tricúspides, endocono de extremidade afilada, com menor comprimento e largura em relação ao mesocono, oval-alongado; ectocono bífido e com extremidades afiladas, restringe-se a aproximadamente metade do comprimento do mesocono (Fig. 16). Fórmulafileira da rádula: $\mathrm{C} / 1+\mathrm{L} 7-8 / 2+\mathrm{M} 23-24 / 2$.

Sistema reprodutor (Fig. 17). Ovarioteste constituída por folículos acinosos, inserida na glândula digestiva, com volume equivalente ao da glândula do albume. Os ductos destes folículos convergem formando
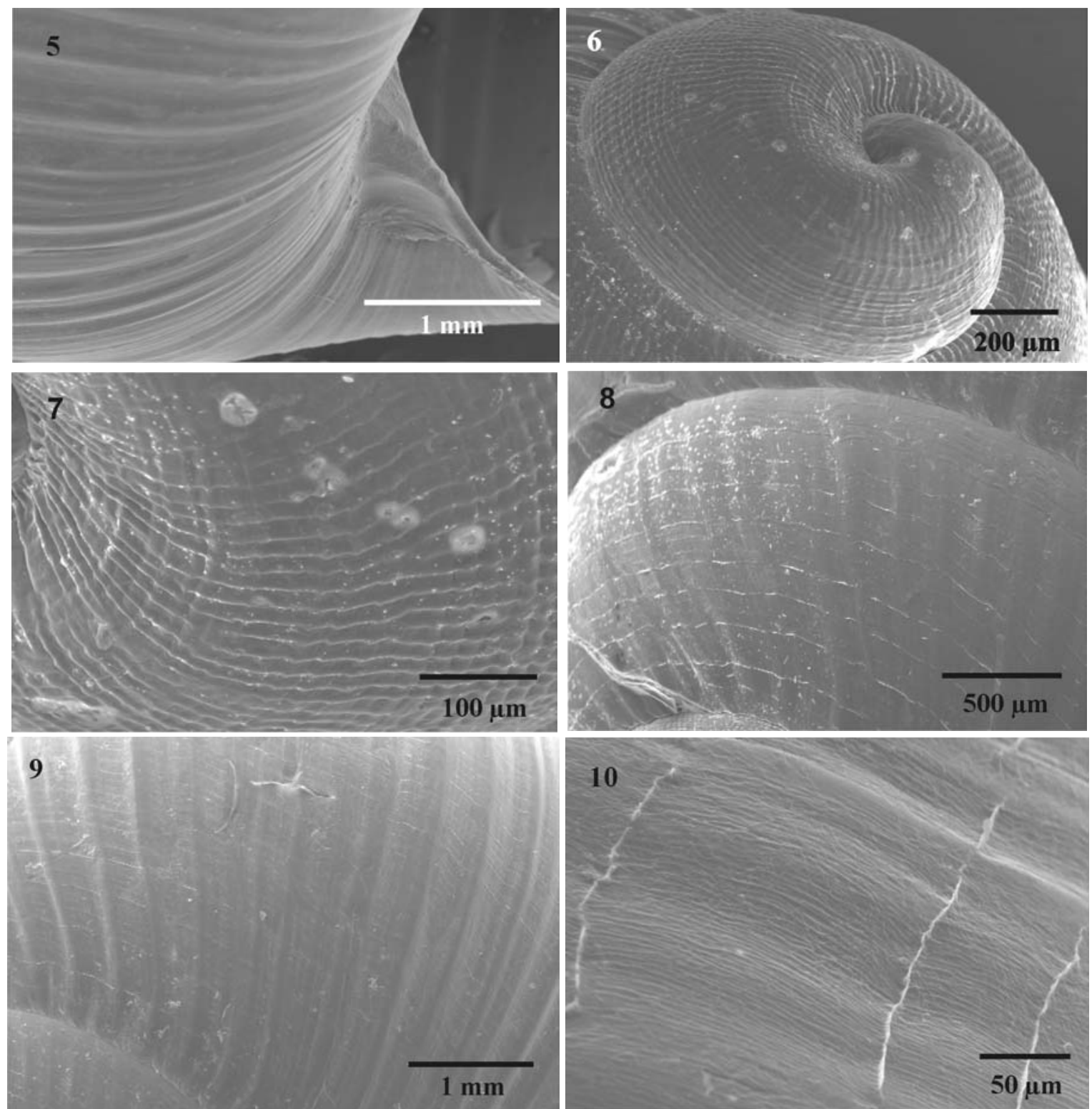

Figs. 5-10. Simpulopsis promatensis sp. nov.: 5, calo columelar; 6, protoconcha; 7, detalhe da esculturação da protoconcha; 8, início da teleoconcha apresentando linhas espirais; 9, detalhe da última volta apresentando as linhas espirais; 10, detalhe das linhas espirais da teleoconcha. 
o ovulispermioducto. Este aumenta rapidamente de calibre, caracterizando a vesícula seminal, cujo diâmetro corresponde a cerca do triplo do ovulispermioducto, logo depois volta a adelgaçar-se, continuando no complexo de fertilização que possui um divertículo. O comprimento da glândula do albume corresponde a cerca de um quinto do ovispermioducto, sua forma é elipsóide e dilatada. Ovispermioducto divide-se em quatro regiões distintas: porção inicial esbranquiçada e com pregueamento sutil; região intermediária avermelhada e com forte pregueamento; região branca hialina, pregueamento semelhante ao da porção anterior; última região branca hialina e sem pregueamento. Do lado oposto ao pregueamento do ovispermioducto, está disposta a glândula prostática esbranquiçada, formada por numerosos ácinos, que se comunica com o canal deferente. A partir do ovispermioducto se origina $o$ oviduto, com comprimento semelhante ao da vagina que o segue, continuando em um átrio que se abre no poro genital. A vagina recebe o falo e emite o ducto da glândula gametolítica na mesma altura. Este ducto inicia com calibre mediano, levemente maior do que o do oviduto; depois se torna extremamente robusto, tendo o dobro desta largura inicial e formato ovalado; por último adelgaçandose bruscamente, tendo uma largura equivalente a um quarto da porção inicial. As duas primeiras porções deste ducto possuem comprimentos semelhantes, mas a última é levemente maior. Esta estrutura termina em uma ovalada glândula gametolítica com cerca de um terço do comprimento de seu ducto. Falo tão longo quanto o ducto da glândula gametolítica e revestido por uma túnica. Evertofalo com cerca da metade do comprimento do epifalo, dilatado e em forma de "U". Epifalo levemente mais delgado que o evertofalo, disposto de modo
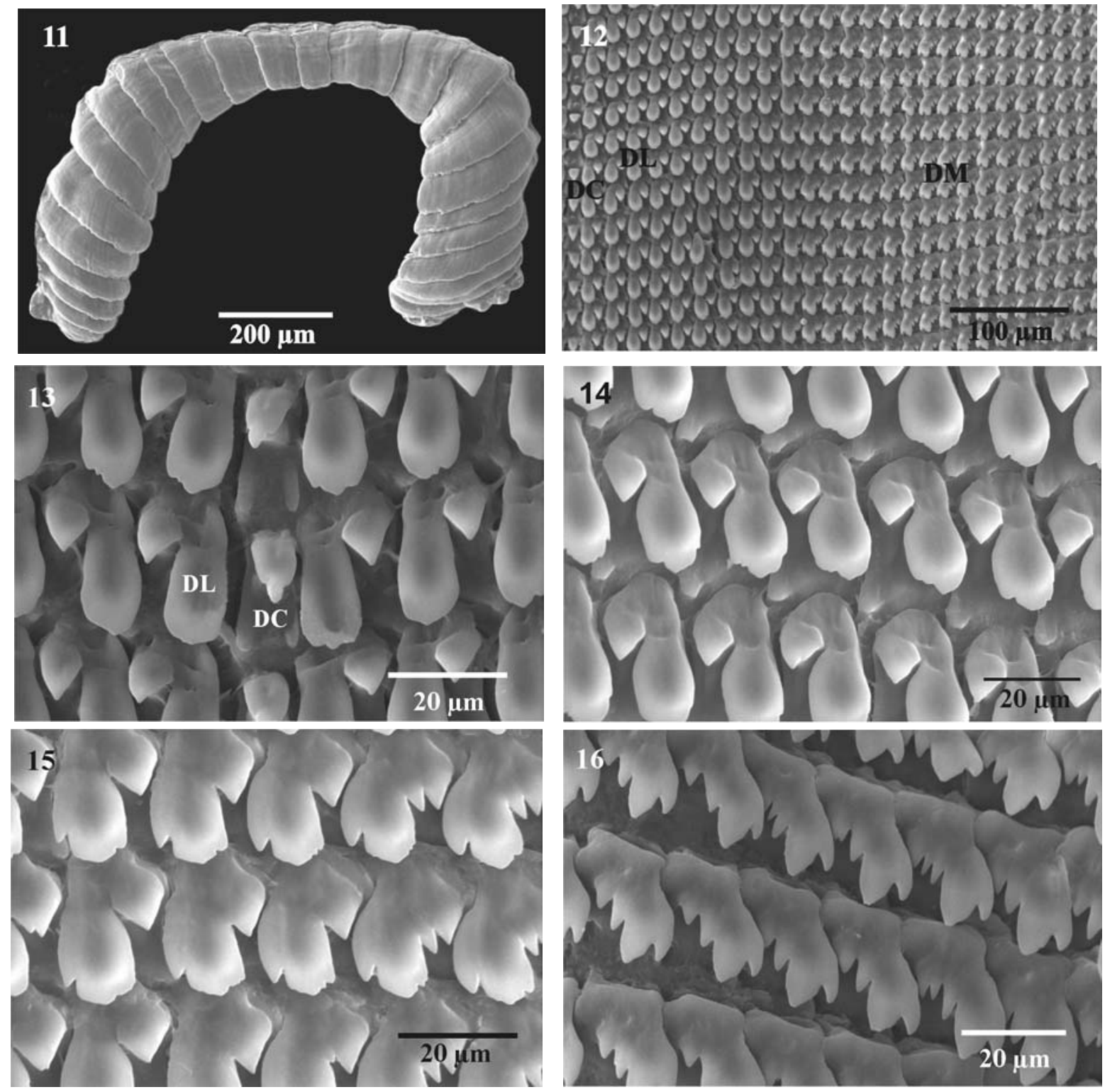

Figs. 11-16. Simpulopsis promatensis sp. nov.: 11, mandíbula (levemente deformada na preparação); 12, disposição dos dentes radulares; 13, dentes centrais ladeados pelos laterais; 14, dentes laterais; 15, transição entre os dentes laterais e os marginais; 16, dentes marginais (DC, dentes centrais; DL, dentes laterais; DM, dentes marginais). 
Tab. I: Valores mínimos, máximos, médias e desvios padrões (dp) das 12 variáveis verificadas de Simpulopsis promatensis sp. nov. ( $\mathrm{n}=48$; valores em milímetros, exceto para o número de voltas). (Dap, distância entre o ápice e a junção da margem parietal superior; Dce, distância entre c e a extremidade; Dp, distância entre a junção da margem parietal superior e a inferior; Ha, altura da abertura; Hc, altura central; Hcl, altura da columela livre; He altura da espira; Hic, altura interna da columela; Ht, altura total $\mathrm{La}$, largura da abertura; Lt, largura total; $\mathrm{N}^{\circ}$ vol., número de voltas).

\begin{tabular}{lcrrc}
\hline & Mín. & Máx. & Média & $\mathrm{dp}$ \\
\hline Dap & 0,40 & 4,71 & 2,95 & 1,66 \\
Dce & 0,50 & 3,89 & 1,79 & 0,98 \\
Dp & 0,60 & 3,89 & 1,92 & 1,00 \\
$\mathrm{Ha}$ & 1,23 & 7,06 & 3,51 & 1,89 \\
$\mathrm{Hc}$ & 1,50 & 10,52 & 4,90 & 2,78 \\
$\mathrm{Hcl}$ & 0,55 & 3,76 & 1,84 & 1,03 \\
$\mathrm{He}$ & 0,20 & 3,91 & 1,57 & 1,01 \\
$\mathrm{Hic}$ & 0,80 & 6,76 & 3,06 & 1,78 \\
$\mathrm{Ht}$ & 1,60 & 10,96 & 5,09 & 2,88 \\
$\mathrm{La}$ & 0,94 & 4,90 & 2,52 & 1,21 \\
$\mathrm{Lt}$ & 1,55 & 8,63 & 4,34 & 2,22 \\
$\mathrm{~N}^{\circ}$ vol. & 1,63 & 4,50 & 3,06 & 0,94 \\
\hline
\end{tabular}

espiralado. Ducto deferente exterioriza-se, delimitando o início do oviduto e prolonga-se junto à face externa do falo, inserindo-se no final do epifalo. Apresenta um pequeno flagelo. $\mathrm{O}$ músculo retrator do falo parte da extremidade e da porção lateral do flagelo, inserindo-se no diafragma.

Cavidade palial (Fig. 18). Possui um rim triangular que compreende aproximadamente um quinto da cavidade palial. Ureter primário, mais curto e alargado do que o ureter secundário, dispõe-se na face direita do rim e após curva-se, originando o ureter secundário, cuja disposição é paralela ao reto, prolongando-se até o ânus. O pericárdio situa-se do lado esquerdo do rim, envolvendo a aurícula e o ventrículo cujos tamanhos são equivalentes. A partir da aurícula segue a veia pulmonar principal que se estende até a região do pneumostômio. Entre a veia pulmonar principal e o ureter secundário há um maior número de vasos secundários do que do outro lado da veia pulmonar principal. Veia marginal, disposta paralelamente por quase toda a extensão do colar do manto, com calibre

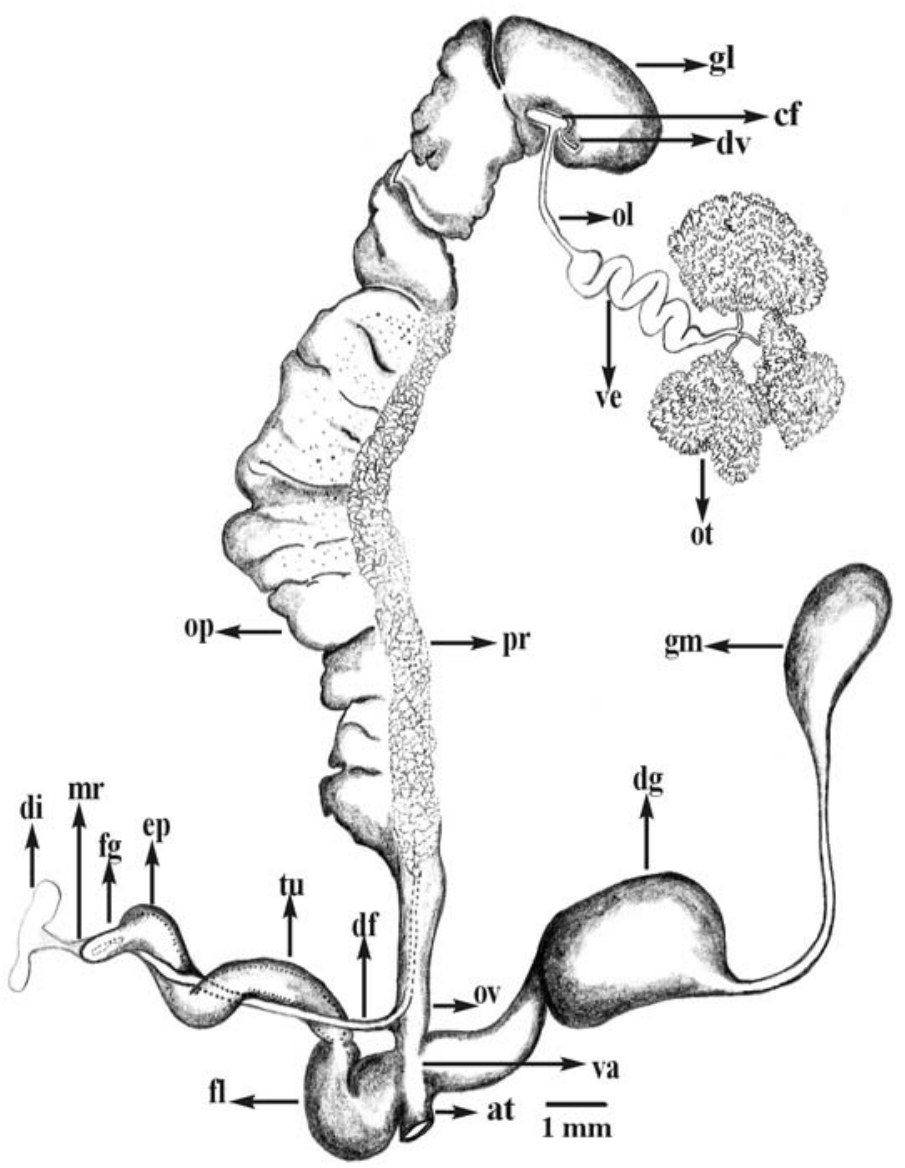

Fig. 17. Sistema reprodutor de Simpulopsis promatensis sp. nov. (at, átrio; cf, complexo de fertilização; df, ducto deferente; dg, ducto da glândula gametolítica; di, porção rasgada do diafragma; dv, divertículo; ep, epifalo; fg, flagelo; fl, evertofalo; gl, glândula do albume; gm, glândula gametolítica; mr, músculo retrator do falo; ol, ovulispermioducto; op, ovispermioducto; ot, ovarioteste; ov, oviduto; pr, próstata; tu, túnica; va, vagina; ve, vesícula seminal). 
intermediário entre a veia pulmonar principal e as veias secundárias.

\section{Simpulopsis gomesae sp. nov. (Figs. 19-32)} Gomes.

Etimologia. Homenagem à colega Suzete Rodrigues

Diagnose. Concha amarela, delgada. Protoconcha com salientes estrias espirais, bem espaçadas entre si; junto à sutura superior evidencia-se uma rugosidade axial que persiste em pequena porção da volta. As estrias espirais se mantêm por toda a concha. Corpo amarelado. Fileiras transversais radulares dispõem-se linearmente.
Dentes radulares tricúspides, os centrais acentuadamente estreitos. Teleoconcha com rugosidade axial linear, levemente acentuada na última volta. Vesícula seminal com largura correspondente a aproximadamente uma vez e meia a do ovulispermioducto; glândula do albume globosa, com um pouco menos da metade do comprimento ovispermioducto.

Material-tipo. BRASIL, Rio Grande do Sul: São Francisco de Paula, J. Thomé/ELMP col.: Holótipo. 29.XI.2003 (MCP 8701). Parátipos. 1 ex., 19.V. 1996 (MCP 7873); 1 ex. 01.XI.19997 (MCP 7776); 1 ex., 21.XI.1998 (MCP 7778); 1 ex., 13.X.2001 (MCP 8706); 2 exs., 14.X.2001 (MCP 8707); 2 exs., 12X.2001 (MCP 8705); 2 exs., 08.XII 2001 (MCP 8704); 1 ex., 09.XII.2001 (MCP 8710); 1 ex., 25.VIII.2002 (MCP

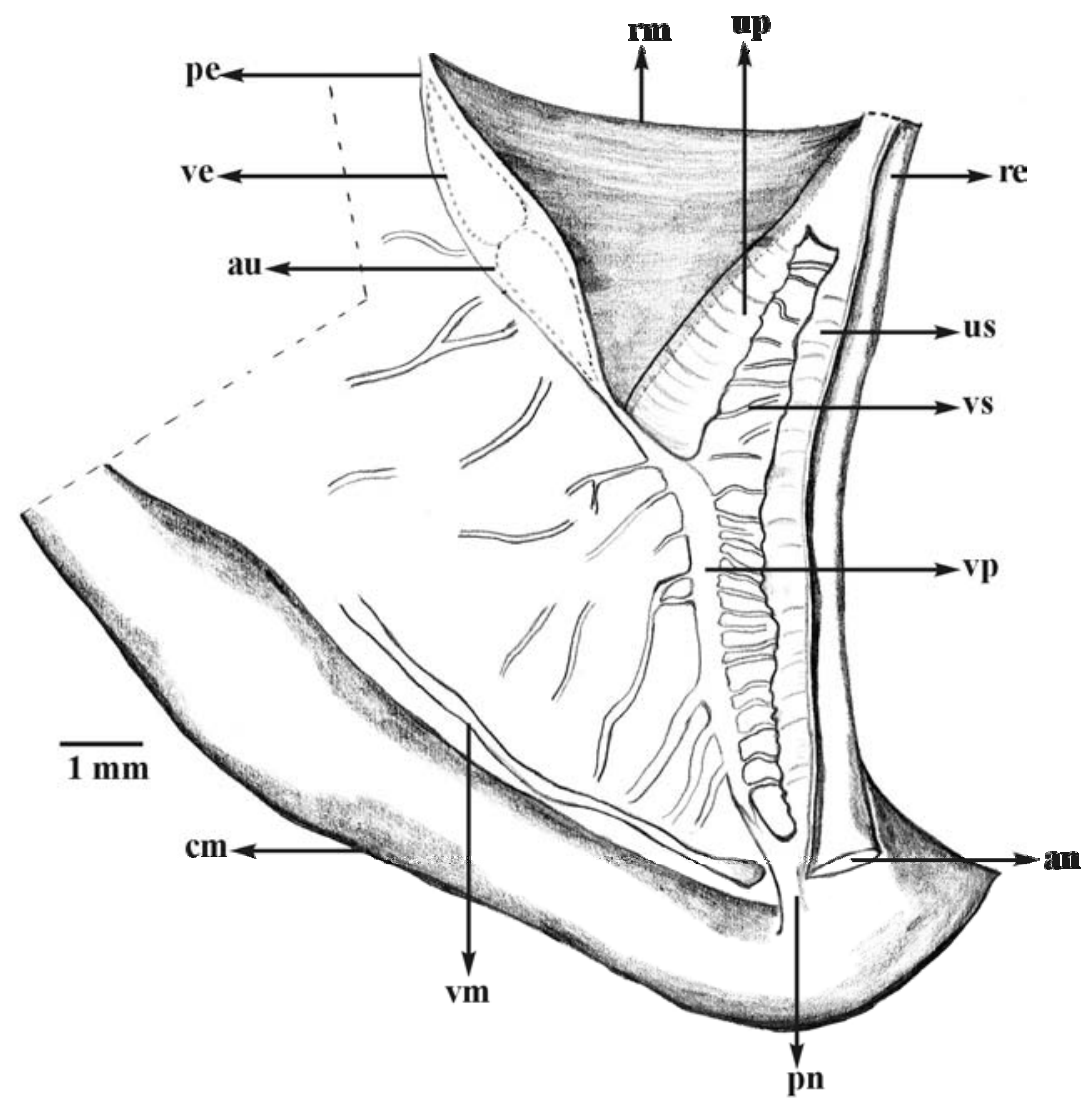

Fig. 18. Cavidade palial de Simpulopsis promatensis sp. nov. (an, ânus; au, aurícula; cm, colar do manto; pe, pericárdio; pn, pneumostômio; re, reto; rm, rim; up, ureter primário; us, ureter secundário; ve, ventrículo; vm, veia marginal; vp, veia pulmonar principal; vs, vasos secundários).

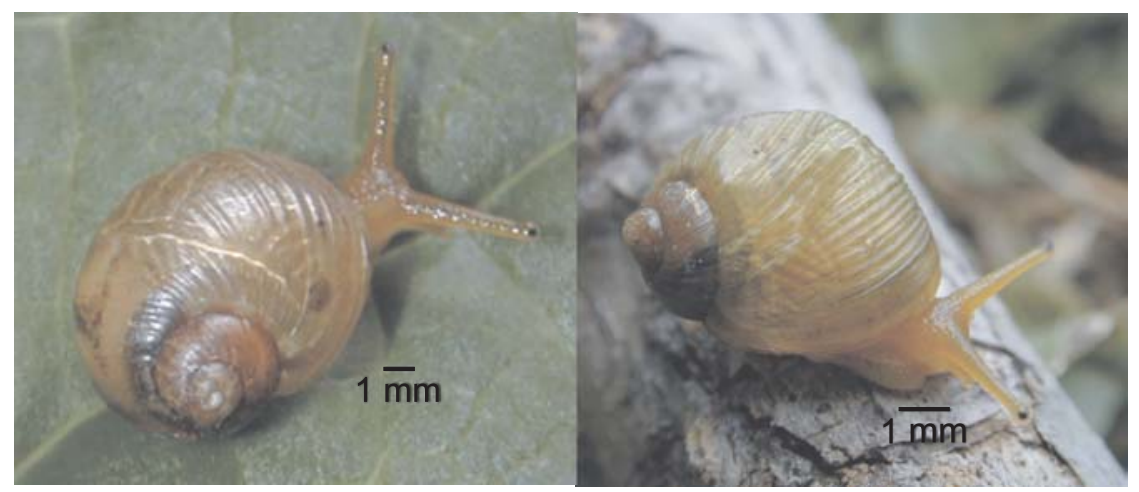

Fig. 19. Espécimes vivos de Simpulopsis gomesae sp. nov. 
8702); 2 exs., 13.X.2002 (MCP 8703); 1 ex., 13.X.2002 (BMNH 20050238 ex MCP 8703); 1 ex., 22.IV.2005 (MCN-FZB 35548); 1 ex., 27.IX.2003 (MCP 8708); 1 ex., 28.IX.2003 (MCP 8709).

Localidade-tipo. Centro de Pesquisas e Conservação da Natureza PRÓ-MATA, São Francisco de Paula, RS, Brasil.

Descrição. Corpo amarelado (Fig. 19). Concha cônica globosa, volta corporal ampla $(\mathrm{Ht} / \mathrm{Lt}=1,16)$; espira com aproximadamente um terço da altura total $(\mathrm{He} /$ $\mathrm{Ht}=0,30)$; columela oblíqua, imperfurada; abertura ovalada $(\mathrm{Ha} / \mathrm{La}=1,31 ; \mathrm{Ha} / \mathrm{Lt}=0,82 ; \mathrm{La} / \mathrm{Lt}=0,62)$ (Tab. II), lábio externo cortante; concha amarelada, frágil e translúcida (Fig. 20). Protoconcha com 1,75 a duas voltas, esculturada por proeminentes estrias espirais bem espaçadas entre si (Figs. 21-23) que se mantêm por toda a superfície da concha (Fig. 24). Rugosidade axial disposta linearmente, acentuada na última volta.

Mandíbula. Arqueada, tendo de 29 a 34 ripas retangulares. Região central constringida, com as ripas fusionadas. A partir das extremidades desta região, as ripas seguintes têm um grande acréscimo quanto à altura, mantendo um tamanho constante a partir da $4^{\mathrm{a}}$ ou $5^{\mathrm{a}}$ ripa seguinte (Fig. 25).

Rádula. Fileiras transversais da rádula com dentes centrais, laterais e marginais dispostos linearmente (Fig. 26). Dentes laterais e marginais possuem tamanhos semelhantes; centrais acentuadamente mais estreitos do que os demais. Dentes centrais tricúspides, tendo mesocono afilado e alongado; ectoconos idênticos (com cerca de um terço da altura e metade da largura do mesocono); apresentam duas projeções laterais na placa basal (Fig. 27). Dentes laterais tricúspides, o mesocono alongado ovalado, com extremidade rombuda, podendo

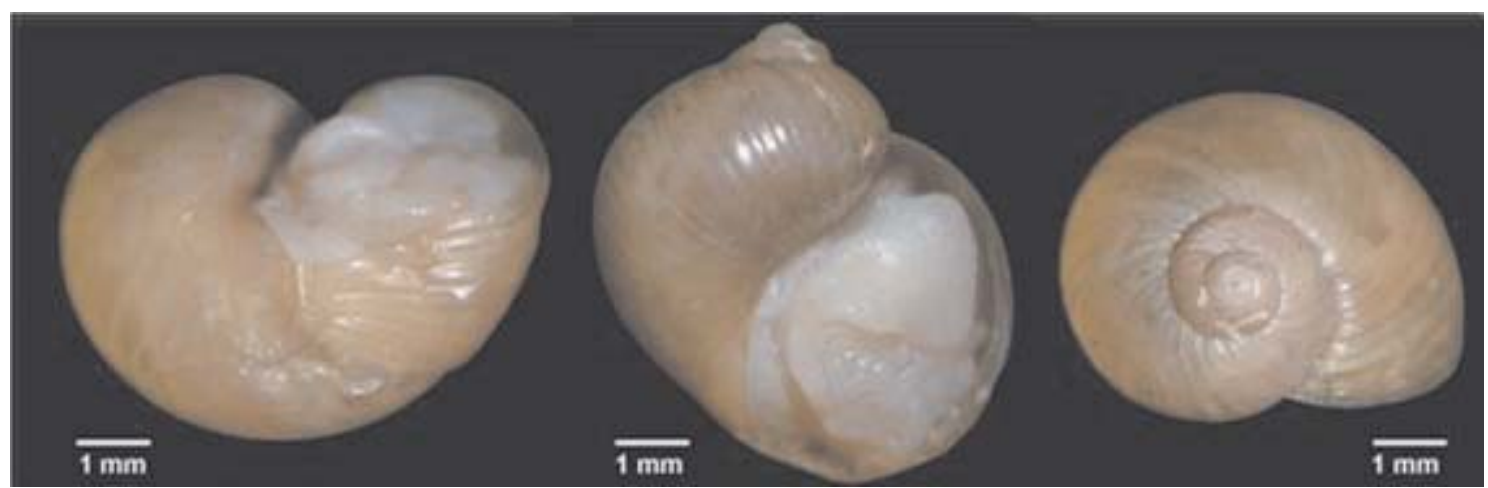

Fig. 20. Holótipo de Simpulopsis gomesae sp. nov., da esquerda para a direita: inferior, frontal e apical.
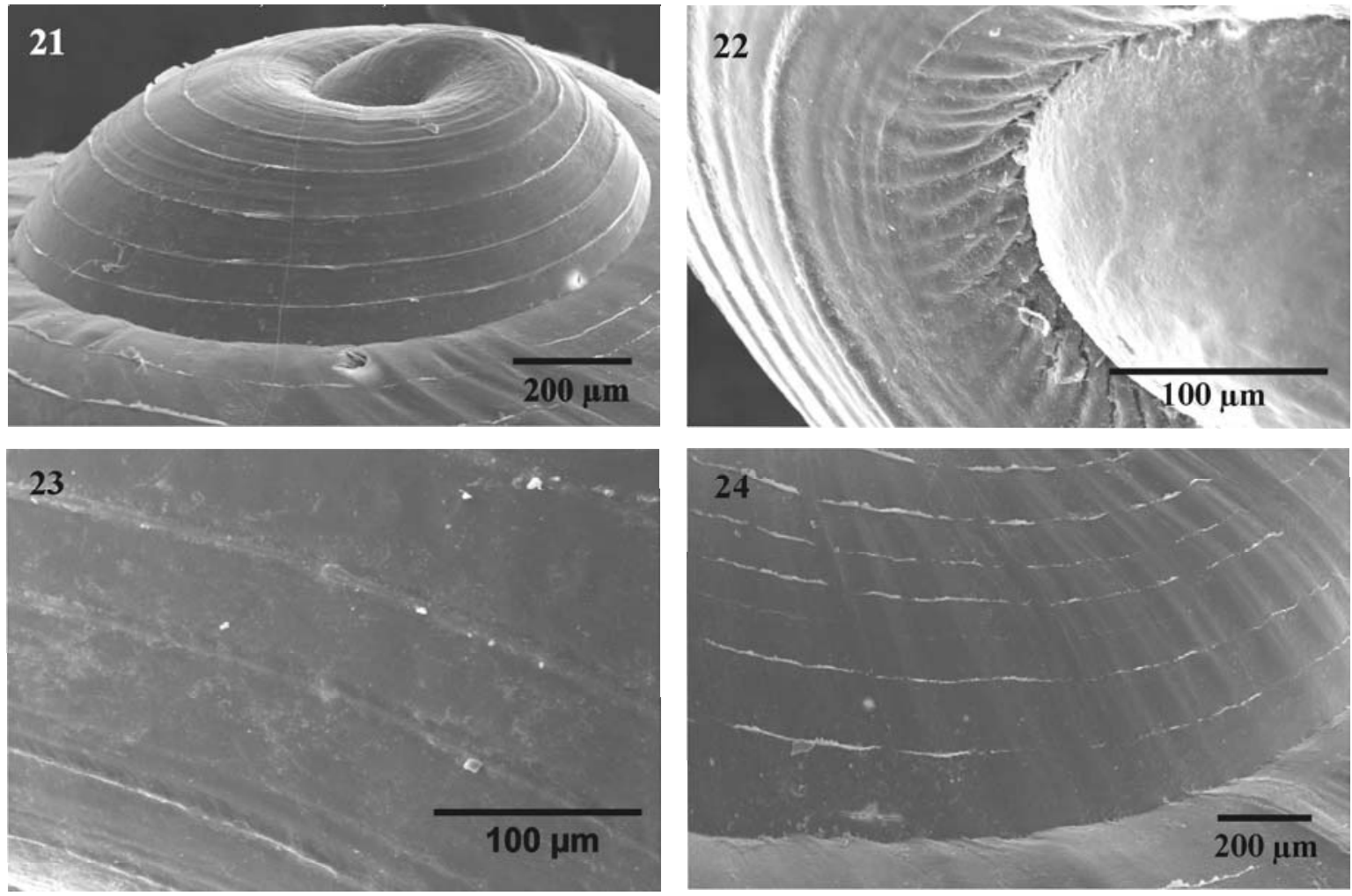

Figs. 21-24. Fotomicrografias da concha de Simpulopsis gomesae sp. nov.: 21, protoconcha; 22, detalhe da esculturação da protoconcha evidenciando a rugosidade axial e as linhas espirais; 23, detalhe das linhas espirais da protoconcha; 24, esculturação da teleoconcha. 
ser bífido; o endocono também oval-alongado, com extremidade igualmente rombuda (altura semelhante a do mesocono e largura levemente menor); o ectocono com forma geral triangular, base arredondada, podendo ser bífido (Fig. 28). Entre os dentes laterais e os marginais há uma série de transição (Fig. 29). Dentes marginais tricúspides, mais alargados do que os demais dentes; o mesocono e o endocono bem semelhantes aos dos dentes laterais, mas diferem pela maior largura existente desde a base do dente; ectocono com extremidade afilada, bífido (Fig. 30). Fórmula-fileira da rádula: C/1+L5-6/2+M62-66/2.

Sistema reprodutor (Fig. 31). Ovarioteste com volume equivalente a menos de $1 / 10$ da glândula do albume, formada por folículos acinosos cujos ductos convergem formando o ovulispermioducto. Este aumenta sutilmente de calibre, caracterizando a vesícula seminal, cujo diâmetro corresponde a aproximadamente uma vez e meia a do ovulispermioducto, depois volta a adelgaçar-
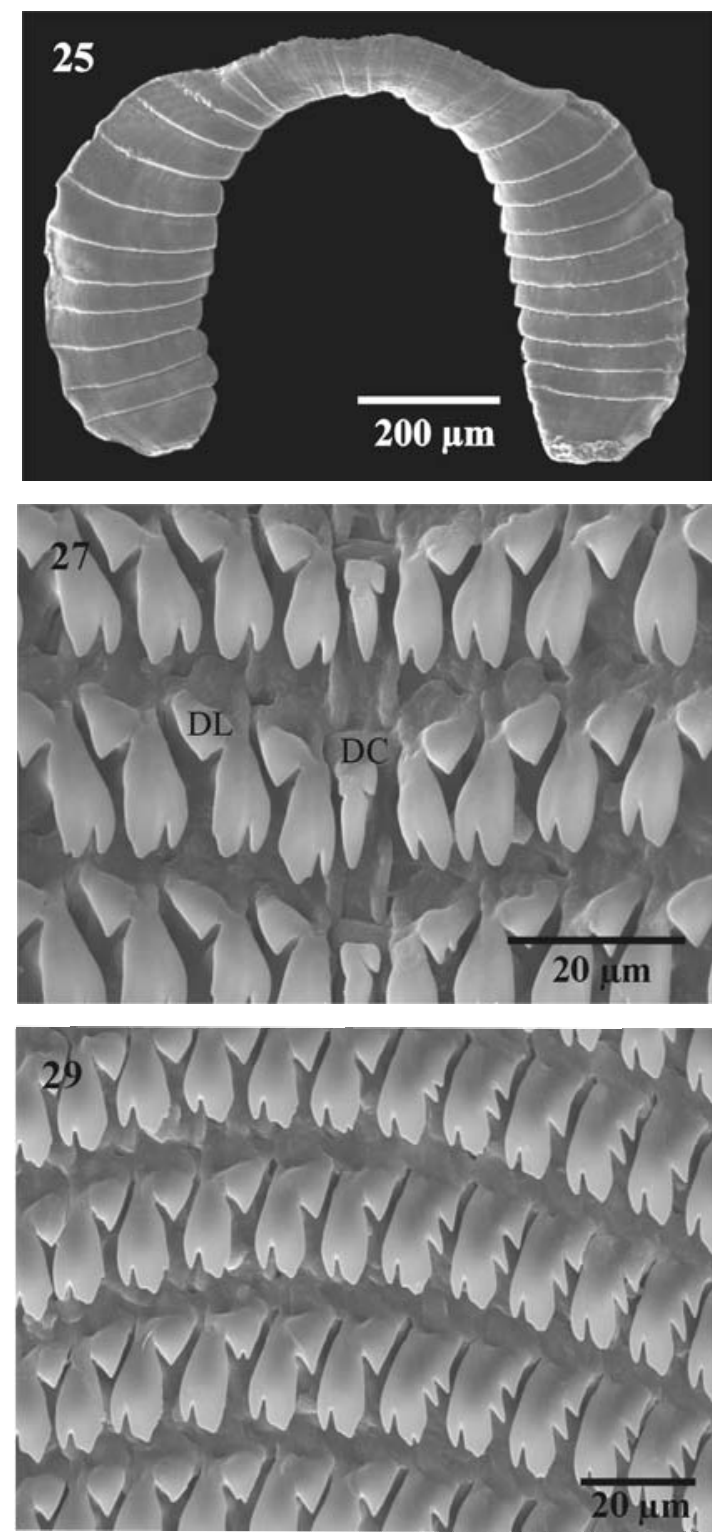

Figs. 25-30. Mandíbula e rádula de Simpulopsis gomesae sp. nov.: 25, mandíbula; 26, disposição dos dentes radulares; 27, dentes centrais ladeados pelos laterais; 28, dentes laterais; 29, série de transição entre os dentes laterais e os marginais; 30, dentes marginais (DC, dentes centrais; DL, dentes laterais; DM, dentes marginais).

se, continuando no complexo de fertilização que possui um divertículo. Glândula do albume globosa, com um pouco menos da metade do comprimento do ovispermioducto cujo pregueamento inicia-se de forma sutil, sendo profundamente recortado na região mediana e tendo uma porção final sem pregueamento. Segue-se um oviduto com cerca de quatro vezes o comprimento da vagina. Do lado oposto ao do pregueamento do ovispermioducto localiza-se a glândula prostática, formada por pequenos ácinos. Do oviduto origina-se uma vagina cuja extremidade une-se ao átrio, desembocando no poro genital. A partir da vagina prolonga-se o ducto da glândula gametolítica com grande calibre inicial, adelgaçando-se na porção mediana e seguindo-se na glândula gametolítica oval-alongada. Logo abaixo da emissão do ducto da glândula gametolítica, o oviduto recebe do lado oposto, o falo, com cerca da metade do comprimento do ducto da glândula gametolítica.
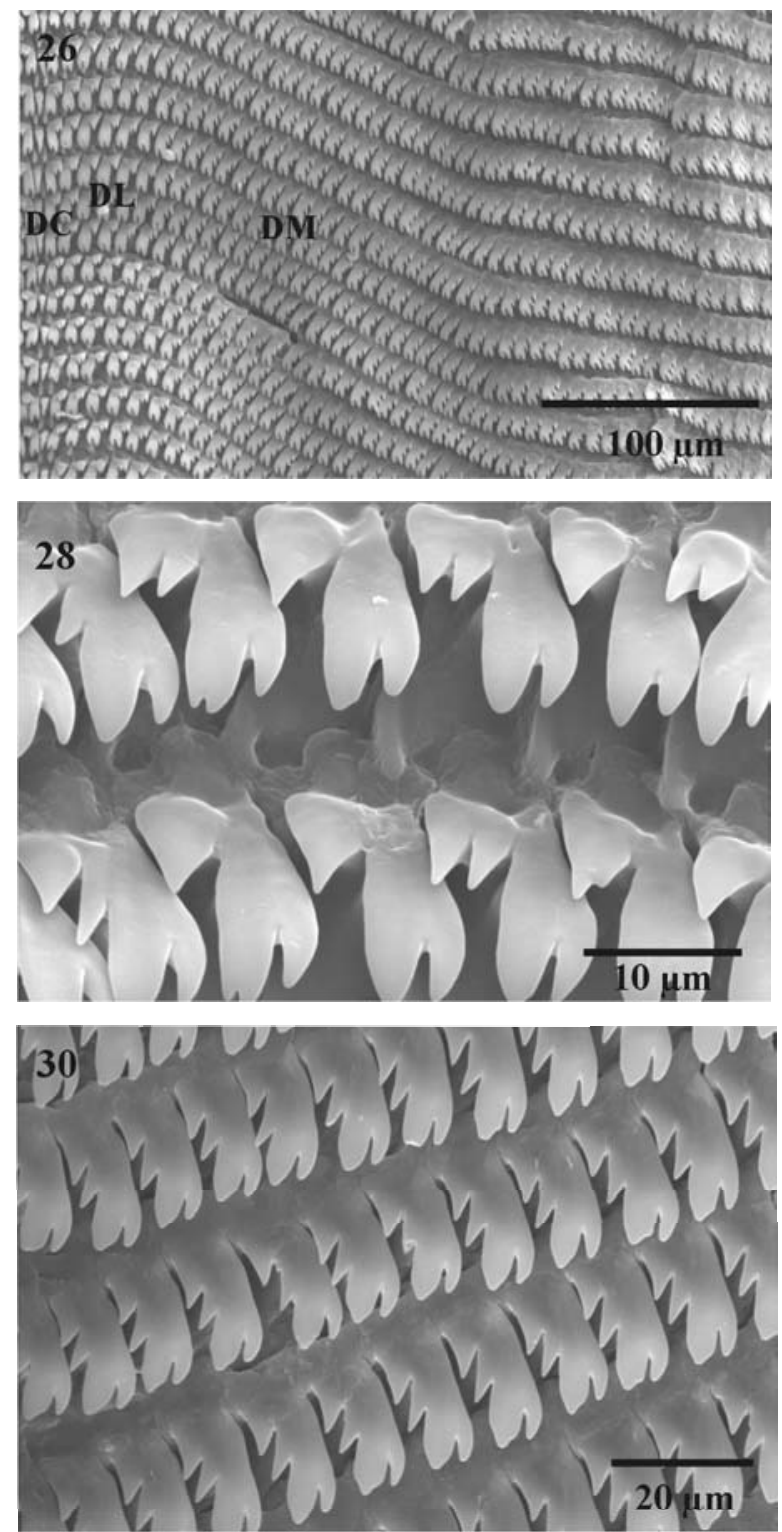
Evertofalo levemente dilatado, possui a metade do comprimento do epifalo. Túnica, formada por um delicado tecido, recobre propinqüamente o evertofalo. Ducto deferente exterioriza-se evidenciando o início do oviduto, prolonga-se junto à face externa do oviduto e do falo,

Tab. II: Valores mínimos, máximos, médias e desvios padrões (dp) das 12 variáveis utilizadas nas análises conquiliomorfométricas de Simpulopsis gomesae sp. nov. ( $\mathrm{n}=14$ valores em milímetros, exceto para o número de voltas) (Dap, distância entre o ápice e a junção da margem parietal superior; Dce, distância entre $c$ e a extremidade; Dp, distância entre a junção da margem parietal superior e a inferior; Ha, altura da abertura; Hc, altura central; Hcl, altura da columela livre; He, altura da espira; Hic, altura interna da columela; Ht, altura total; La, largura da abertura; Lt, largura total; $\mathrm{N}^{\circ}$ vol., número de voltas)

\begin{tabular}{lcrcc}
\hline & Mín. & Máx. & Média & dp \\
\hline Dap & 1,24 & 3,56 & 2,12 & 1,07 \\
Dce & 1,40 & 3,34 & 2,10 & 1,04 \\
Dp & 1,60 & 3,88 & 2,43 & 1,21 \\
$\mathrm{Ha}$ & 2,93 & 7,24 & 4,48 & 2,25 \\
$\mathrm{Hc}$ & 3,73 & 9,17 & 3,77 & 3,36 \\
$\mathrm{Hcl}$ & 1,32 & 3,59 & 2,23 & 1,16 \\
$\mathrm{He}$ & 0,87 & 3,04 & 1,69 & 0,91 \\
$\mathrm{Hic}$ & 2,18 & 5,81 & 3,55 & 1,79 \\
$\mathrm{Ht}$ & 3,86 & 10,28 & 6,17 & 3,15 \\
$\mathrm{La}$ & 2,23 & 5,52 & 3,44 & 1,71 \\
$\mathrm{Lt}$ & 3,63 & 8,87 & 5,55 & 2,75 \\
$\mathrm{~N}^{\circ}$ vol. & 2,58 & 4,10 & 2,92 & 1,33 \\
\hline
\end{tabular}

inserindo-se na região mediana do epifalo. Flagelo com extremidade rombuda. Na lateral do flagelo insere-se o músculo retrator do falo preso no diafragma.

Cavidade palial (Fig. 32). Dorsalmente sob o manto, na região posterior da cavidade palial, entre o reto e o pericárdio, localiza-se o rim triangular; seu tamanho corresponde a aproximadamente um quinto da cavidade palial. Ureter primário, mais curto e levemente mais alargado do que o ureter secundário, dispõe-se na face direita do rim e, após, curva-se, originando o ureter secundário, cuja disposição é paralela ao reto até o ânus. Pericárdio situado ao lado esquerdo do rim, envolvendo a aurícula e o ventrículo, cujos tamanhos são equivalentes. A partir da aurícula segue a veia pulmonar principal, que se estende até a região do pneumostômio. Entre a veia pulmonar principal e o ureter secundário há um maior número de vasos secundários do que entre esta veia e o colar do manto. Veia marginal, de calibre intermediário entre os vasos secundários e a veia pulmonar principal, disposta paralelamente ao colar do manto.

Discussão. Diferem das novas espécies quanto à forma geral da concha: $S$. atrovirens (Moricand, 1836), $S$. ovata (Sowerby, 1822), S. brasiliensis (Moricand, 1836), S. miersi (Pfeiffer, 1856) por serem mais largas do que altas, terem espira baixa e abertura oblíqua (MORICAND, 1836; ARAúJo \& BREURE, 1977).

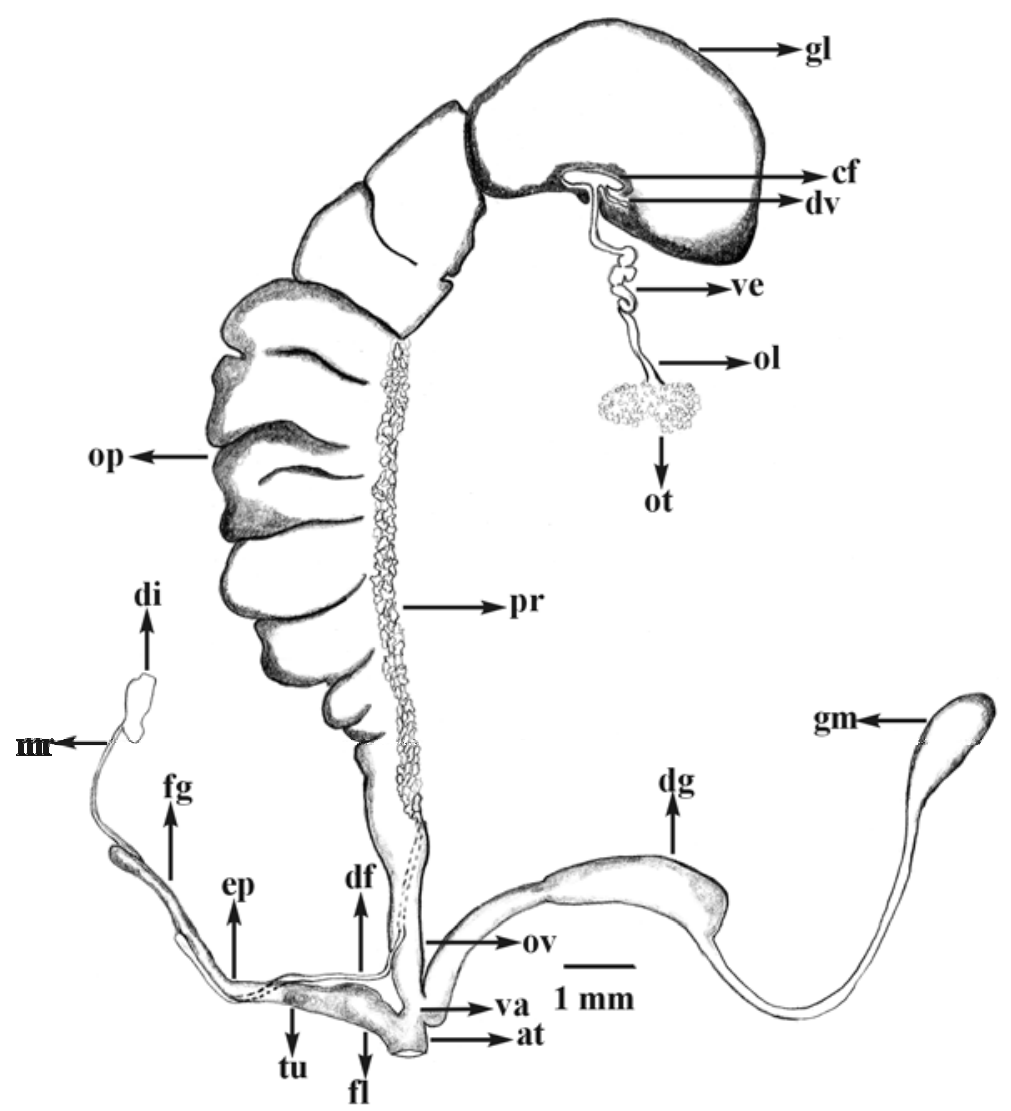

Fig. 31. Sistema reprodutor de Simpulopsis gomesae sp. nov. (at, átrio; cf, complexo de fertilização; df, ducto deferente; dg, ducto da glândula gametolítica; di, porção rasgada do diafragma; dv, divertículo; ep, epifalo; fg, flagelo; fl, evertofalo; gl, glândula do albume; gm, glândula gametolítica; mr, músculo retrator do falo; ol, ovulispermioducto; op, ovispermioducto; ot, ovarioteste; ov, oviduto; pr, próstata; tu, túnica; va, vagina; ve, vesícula seminal). 
Quanto à esculturação da concha, distinguem-se das novas espécies: S. pseudosulculosa Breure, 1975, cuja teleoconcha possui rugosidade axial forte, pouco sinuosa e estrias espirais delicadas, e a protoconcha tem linhas espirais e axiais densas, com uma fina rugosidade (BREURE, 1975); S. wiebesi Breure, 1975 tem protoconcha com linhas axiais irregulares cruzadas por linhas espirais da mesma intensidade e tipo (Breure, 1975); $S$. brasiliensis (Moricand, 1836), pela ausência de esculturação na espira (PILSBRY, 1899); S. decussata (Pfeiffer, 1857), pela presença de linhas espirais cruzadas por algumas linhas oblíquas (PILSBRY, 1899); S. magnus Thompson, 1957 distingue-se das novas espécies devido ao desenho castanho-avermelhado disposto espiralmente na superfície da concha amarela (THOMPSON, 1957); $S$. rufovirens (Moricand, 1846) pela espira não-esculturada (Reeve, 1862; Pilsbry, 1899); S. tryoni Pilsbry, 1899 por ter estrias espirais delgadíssimas (PILSBRY, 1899).

Diferem de $S$. promatensis as espécies: $S$. decussata (Pfeiffer, 1857), S. pseudosulculosa Breure, 1975, S. rufovirens (Moricand, 1846) e S. tryoni (Pilsbry, 1899), que não possuem calo columelar (GuPPY, 1866; REEve, 1862; Pilsbry, 1899; BREURE, 1975).

Distinguem-se das espécies aqui propostas, quanto à anatomia: S. miersi (Pfeiffer, 1856), por suas fileiras transversais radulares dispostas em "V", dentes centrais unicúspides com mesocono ovalado (ARAúJo \& BREURE, 1977); S. ovata, por apresentar distinto padrão de coloração do manto constituído por manchas negras (Araúso, 1975; Gomes et al., 2004); S. pseudosulculosa Breure, 1975, cuja glândula gametolítica é triangularalongada (BREuRE, 1975); S. sulculosa (Férussac, 1821), por ter uma glândula gametolítica globosa e curta, glândula do albume alongada e apresentar dois músculos retratores do falo (BREURE, 1975); S. wiebesi Breure, 1975, por seu evertofalo ondulado e inserção distal do músculo retrator do falo no flagelo (BREURE, 1975) e pelos dentes centrais radulares com mesocono lanceolado, cujos ectoconos são pequenos e destacados do mesocono (BReure \& Ploeger, 1977).

As espécies aqui propostas diferenciam-se entre si em diversos aspectos. Simpulopsis promatensis possui concha marrom, levemente espessa, com calo columelar, protoconcha com estrias espirais regularmente distribuídas e cruzadas por estrias axiais, teleoconcha com estrias espirais interrompidas e irregularmente distribuídas, rugosidade axial retilínea que se acentua gradativamente a cada volta; $S$. gomesae apresenta concha amarela e delgada, proto- e teleoconcha com salientes estrias espirais bem espaçadas entre si, junto à sutura superior evidencia-se uma rugosidade axial que persiste em pequena porção da volta, sua teleoconcha possui rugosidade axial linear levemente acentuada na última volta. Quanto à coloração do corpo, S. promatensis apresenta-se marrom, escurecida na região nucal, omatóforos negros; S. gomesae possui cor suave e

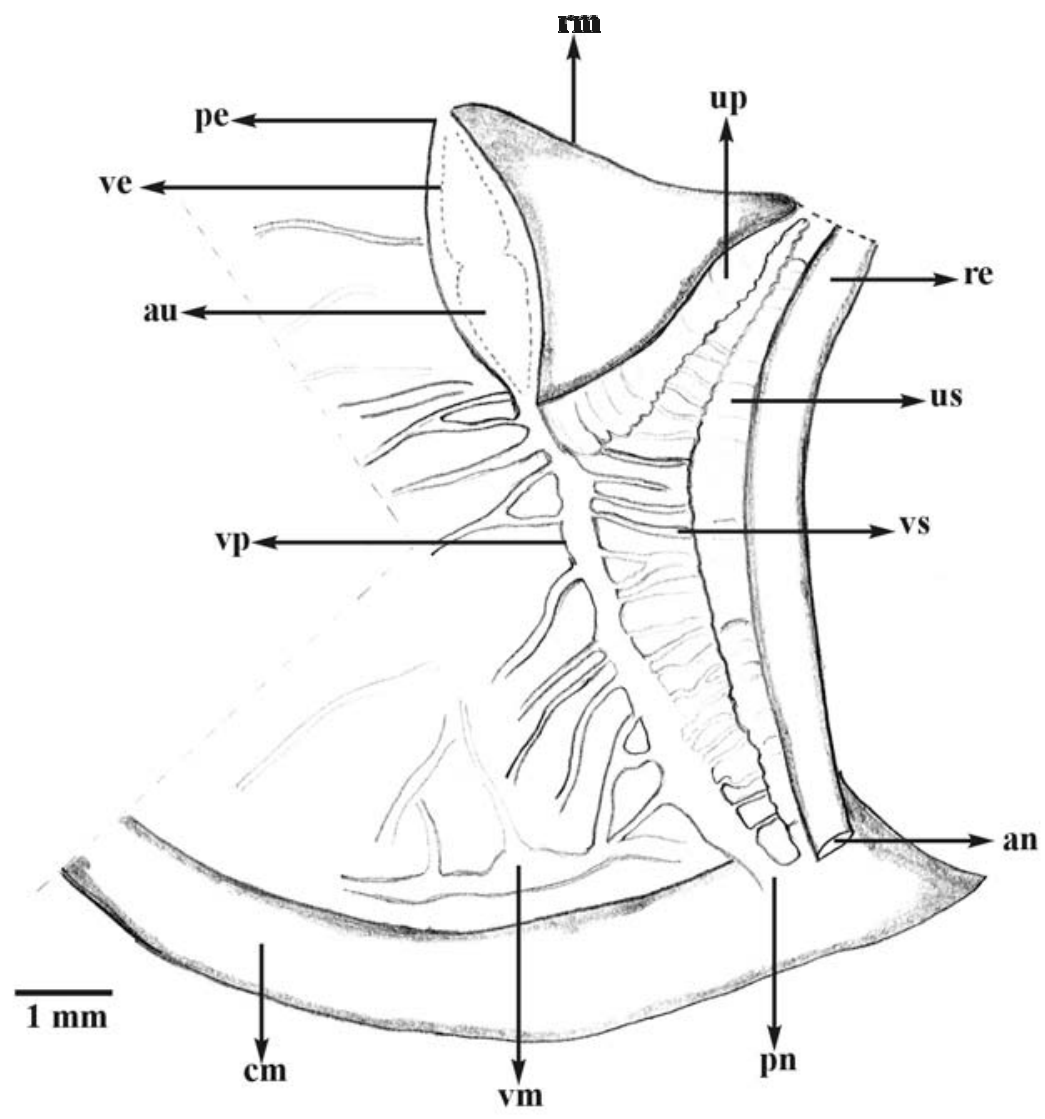

Fig. 32. Cavidade palıal de sımpuıopsıs gomesae sp. nov. (an, anus; au, aurıcuıa; cm, colar do manto; pe, perıcardı; pn, pneumostômio; re, reto; rm, rim; up, ureter primário; us, ureter secundário; ve, ventrículo; vm, veia marginal; vp, veia pulmonar principal; vs, vasos secundários). 
constante.

A rádula de $S$. promatensis apresenta região central com fileiras transversais dos dentes centrais e laterais dispostos levemente em forma de "V"e os dentes marginais dispostos linearmente. Simpulopsis gomesae possui fileiras transversais radulares dispostas linearmente. Quanto à forma e tamanho proporcional dos dentes, em $S$. promatensis os laterais e marginais têm tamanhos semelhantes, os centrais são menores, os centrais e marginais são tricúspides e os laterais bicúspides; na outra espécie, os dentes radulares são todos tricúspides, os dentes centrais diferenciam-se por serem acentuadamente estreitos.

Quanto à anatomia do sistema reprodutor, destacam-se as seguintes diferenciações: $S$. promatensis possui vesícula seminal cujo diâmetro corresponde a cerca do triplo do ovulispermioducto; já em $S$. gomesae o diâmetro da vesícula seminal corresponde a aproximadamente uma vez e meia a do ovulispermioducto; o oviduto de $S$. gomesae possui cerca de quatro vezes o comprimento da sua vagina e em $S$. promatensis, o oviduto e a vagina têm comprimento semelhante; o falo de $S$. promatensis é tão longo quanto o ducto da glândula gametolítica, em $S$. gomesae o falo tem comprimento equivalente à metade do ducto da glândula gametolítica.

Agradecimentos. Ao CNPq, por ter concedido a bolsa de mestrado à autora sênior e pelos auxílios essenciais a este trabalho.

\section{REFERÊNCIAS BIBLIOGRÁFICAS}

Araújo, J. L. B. 1975. Superfamília Bulimuloidea do Brasil. Amphibulimidae: Simpulopsis ovata (Sowerby, 1822). Arquivos do Museu Nacional 55:15-20.

Araújo, J. L. B. \& Breure, A. S. H. 1977. Notes on Bulimulidae (Gastropoda, Euthyneura), anatomy and histology of Simpulopsis (Simpulopsis) miersi Pfeiffer, 1856. Zoologische Mededelingen 52(3):19-25

Bertoletti, J. J. \& Teixeira, M. B. 1995. Centro de Pesquisa e Conservação da Natureza Pró-Mata. Divulgação do Museu de Ciências e Tecnologia - UBEA/PUCRS 2:1-47.

Breure, A. S. H. 1975. Notes on Bulimulidae (Gastropoda, Euthyneura), 2. On small collection of Simpulopsis Beck, 1837, from Southern Brazil, with description of three new species. Basteria 39:97-113.

1979. Systematics, phylogeny and zoogeography of Bulimulinae (Mollusca). Zoologische Verhandelingen (168):1-215.

Breure, A. S. H. \& Ploeger, S. 1977. Notes on Bulimulidae (Gastropoda, Euthyneura), 6. The structure of the radula in some Simpulopsis species. Basteria 41:59-64.

Gomes, S. R.; Silva, R. S. DA; GiL, G. M. \& Thомé, J. W. 2004. Ciclo biológico de Simpulopsis ovata (Gastropoda, Bulimulidae) em São Francisco de Paula, Rio Grande do Sul, Brazil. Iheringia, Série Zoologia, 94(3):253-259.

Guppy, R. J. L. 1866. On the terrestrial and fluviatile Mollusca of
Trinidad. Annals and Magazine Natural History 17:4256.

Moricand, S. 1836. Troisième supplément au mémoire sur les coquilles terrestres et fluviates de la province de Bahia. Société de Physique et d'Historie naturelle de Genève 7:415-446.

_. 1846. Troisième supplément au mémoire sur les coquilles terrestres et fluviates de la province de Bahia. Société de Physique et d'Historie naturelle de Genève 11:147160 .

Pfeiffer, L. 1848. Monographia Heliciorum Viventium. Lipsiae, F. A. Brackhaus. v. 2, 594p. 1853. Diagnosen neuer Heliceen. Zeitschrift für Malakozoologie 10:51-58.

1856a. Versuch einer Anordnung der Heliceen nach natürlichen Gruppen. Malakozoologische Blätter 2:112185.

1856b. Diagnosen interessanter Novitäten. Malakozoologische Blätter 3:256-261.

$1856 \mathrm{c}$. Descriptions of twenty-seven new species of landshells collected by M. Sallé in the state of Vera Cruz, Mexico. Proceedings of the Zoological Society of London 24:318324.

1858. Beiträge zur Fauna von Westindien. Malakozoologische Blätter 5:135-155.

1859. Monographia Heliciorum Viventium. Lipsiae, F. A. Brackhaus. v. 4, 920p.

1861a. Description of fifty-seven new species of land-shells from the collection of $\mathrm{H}$. Cuming, Esq. Proceedings of the Zoological Society of London 20-29.

1861b. Diagnosen neuer Heliceen. Malakozoologische Blätter 8:77-84.

1868. Monographia Heliciorum Viventium. Lipsiae, F. A. Brackhaus. v. 5, 565p.

1876. Monographia Heliciorum Viventium. Lipsiae, F. A. Brackhaus. v.7, 674p.

Pilsbry, H. A. 1899. American Bulimulidae: North American and Antillean Drymaeus, Leiostracus, Orthalicinae and Amphibuliminae. In: Tryon, G. W., Jr. \& Pilsbry, H. A. Manual of conchology structural and systematic. Philadelphia, Academy of Natural Sciences of Philadelphia. v. $12,258 \mathrm{p}$.

Ploeger, S. \& Breure, A. S. H. 1977. A rapid procedure for preparation of radulae for routine research with the Scanning Electron Microscope. Basteria 41:47-52. ReEve, L. A. 1849. Conchologia Iconica: Monograph of the genus Bulimus. Londres, L. A. Reeve, F. L. S. \& F. Z. S. v. 5 [n.num.].

1862. Conchologia Iconica: Monograph of the genus Simpulopsis. Londres, L. A. Reeve, F. L. S. \& F. Z. S. v. 13 [n.num.].

Salgado, N. C. \& Coelho, A. S. C. 2003. Moluscos terrestres do Brasil (Gastrópodes operculados ou não, exclusive Veronicellidae, Milacidae e Limacidae). Revista de Biologia Tropical 51:149-189.

Smith, E. A. 1896. A list of the land and freshwater Mollusca of Trinidad. Journal of Conchology 8:231-251.

Thiele, J. 1963. Handbuch der systematischen weichtierkunde. Amsterdam, A. Asher. v. 2, 1189p.

Thompson, F. G. 1957. A collection of mollusks from northern Venezuela. Occasional Papers of Museum of University of Michigan (591):1-10.

Zilch, A. 1960. Euthyneura. In: WenZ, W. ed. Gastropoda. Berlin, Gerbrüder Borntraeger. n. 2, 834p.

Recebido em junho de 2005. Aceito em abril de 2006. ISSN 0073-4721

Artigo disponível em: www.scielo.br/isz 